\title{
Research on the Application of the Wechat Platform in College Student Management
}

\author{
Hua $\mathrm{Li}^{1, \mathrm{a}}$, Lina Zhou ${ }^{2, \mathrm{~b}}$ and Yueming Yuan ${ }^{3, \mathrm{c}^{*}}$ \\ ${ }^{1,2,3}$ College of engineering and technology, Jilin Agricultural University
}

Xincheng Street 2888, Jilin Agricultural University, Changchun, Jilin Province 130118, PR China

a1544543@163.com, ’yym_jlu@163.com

*The Corresponding author

Keywords: WeChat public platform; College student management; Application program

\begin{abstract}
The current microblogging public platform has become an important carrier of college student management, which has rich information resources and flexible interactive management form. This paper aims at the advantages and application of Wechat platform in the management of college students, and points out that the college student management workers must deeply understand the new media advantages represented by the WeChat public platform and scientifically utilize the new media technology to improve the management of college students Work effectiveness.

WeChat as a Tencent Inc in 2011 launched a smart terminal based on instant messaging application, can support single and multiplayer mobile terminal, users send audio, through intelligent video, pictures and text, and also can through the "public platform", "achieve content sharing circle of friends, and the third party platform. So the favor and recognition by the majority of users. Time by the end of 2016, micro-registered users have reached 821 million people ${ }^{[1]}$. The college students in college as the most positive and rapid to accept new things, the number of WeChat use is very large.The management of college students not only includes the students' ideological and political education work, but also the daily management of students, including class management, career planning, difficult students help, employment guidance and course notification.It can be seen that the management of college students is very cumbersome, and with the WeChat of the popularity of the application of a very high tool platform, you can achieve the management of college students from the simple, while students are more willing to accept and cooperate.
\end{abstract}

\section{The Advantages of the WeChat Public Platform in the Management of College Students}

Has a Common Audience, Rich in Information Resources. According to the National Education in China published in 2016, "China Higher Education Quality Report" results show that in 2015 the total number of college students in China has reached 37 million people, ranking first in the world. According to the China Internet Center released the "26th China Internet Development Statistics Report" we can see that the current number of college students online groups reached the total number of Internet users around 30\%, which compared with other types of groups and the number is undoubtedly huge. It is because of the large number of college students, but also makes the Wechat platform with a universal audience. In the WeChat as the representative of the new media after the emergence of college students quickly become the study and life of important information access and communication platform. Especially in the intelligent collection, $4 \mathrm{G}$ network business as the representative of the rise of the mobile Internet, making Wechat platform is widely used by college students, with a large amount of market space for mining. And college student managers can send a variety of forms of information through the WeChat public platform, including voice, video, pictures and text, you can also share the content of the link, making the information resources more rich and intuitive, and the actual life of college students close to each other. And the information once released, you can reach the first time WeChat platform users, synchronization is very high, which has a good accuracy and effectiveness ${ }^{[2]}$. 
Support Equal Interaction, Flexible and Private way of Communication. Through the WeChat platform for information transmission, can be avoided by the time and space constraints. In the traditional college student management work, the basic are to take a limited carrier to carry out daily work, such as meetings, course learning and submission of materials, whether it is time or place, are obvious restrictions. And under the Wechat platform, can at any time, any place with the students to interact with each other, fully mobilize teachers and students to take the initiative and enthusiasm, so as to greatly enhance the efficiency of college student management. In particular, under the condition that the number of college students is large and the number of student management staff is insufficient, student managers can realize the one-to-many daily management work, including the task of communication, the reminder and the thought, by means of the technical support provided by the Wechat platform communication and so on. But also to achieve one-on-one depth of counseling, such as students by WeChat public platform to submit the problem, with good flexibility and privacy, which significantly enhance the effectiveness of student management ${ }^{[3]}$.

Have Good Data Statistics Function, Easy to Quantify the Assessment. In the college student management work, the most important part is to take rigid institutional arrangements, the behavior of students to be standardized, implement the management responsibility, and gradually develop a good culture of execution. In this imperative system of protection, in order to fully mobilize the positive initiative of teachers and students, but also supplemented by scientific quantitative assessment, making the effectiveness of college student management work has been effectively improved ${ }^{[4]}$.In practice, Wechat platform has a good statistical function, including the message analysis, user analysis and graphic analysis of them ${ }^{[5]}$.Among them, the message analysis is a real-time view of the user to send out the message and statistics, including the number of messages sent and the number of times; And user analysis is the statistical view of each time period among the number of users growth, attention to cancellation and identity attributes and other content; As for the graphic analysis is for the mass of the graphic message analysis, view the various time period of the text message effect. The Wechat public platform exists in the form of the developer's public number, which can directly view the interface and invoke the statistical data, which can promote the comprehensive analysis and deepening of the statistical analysis, which not only can effectively reduce the workload of college student management staff, but also to facilitate the quantitative assessment.

\section{The Application Scheme of the Wechat Platform in the Management of College Students}

In the opening and application of Wechat platform, which can help the management of college students to provide new ideas and models. In this case, specifically to Jilin Agricultural University WeChat public platform as an example, in the student management put forward the following applications:

Set Up Auxiliary Management Functions. The WeChat's public platform has the auxiliary management functions, including micro courses as well as teacher-student Q\&A exchanges and so on. Which can provide a platform for interactive communication between teachers and students. In the traditional college student management work, students are as passive recipients, and student management workers are blindly upload and release, generally only a special time node communication opportunities, as other times cannot be fully communication, Students' daily learning and living conditions cannot be understood by management workers. In the creation of micro-public platform after the auxiliary management functions, students and managers can communicate anytime, anywhere, including text, language, etc., so that students can be based on the actual situation of students in the actual situation of the Q \& A problem, The actual situation of the student. Especially for some special needs of the students, but also at any time to carry out management work.

Make Full Use of the Fallang and the Message Board. In the Wechat platform, you can make full use of the Fallang and the message board for students to recommend popular books, hot comments and performance inquiries, teachers and students can also be interactive browsing and grasp key information. This will allow college students to play WeChat in the process, consciously 
unconsciously accept the necessary management, and to absorb knowledge and information. With the help of "comment" function, it is possible to further deepen the interaction between college students and students, especially for some hot spots of ideological and political education to focus on discussion, through positive, healthy and optimistic ideas to guide students to make it can be subtle in the cultivation of the correct outlook on life and value, to avoid the negative impact of the negative impact of low wind.

Improve the Speed of Information Dissemination, to Facilitate the Daily Handling of Students. College student management workers should use the WeChat public platform, at any time to some of the student management information, news, national policy policy, technology frontier, employment situation, school dynamics, PubMed information, civil service enrollment information, employing units and other valuable information Released, so that you can "concerned about" the school WeChat public platform students at any time to understand, but also can use the students between each other "attention", at any time released to the circle of friends, improve the speed of information dissemination. And then should make full use of WeChat public platform provided by the developer model, for the implementation of secondary development of WeChat function, and the school elective management system, the results query system, dormitory management system and other seamless docking, so as to maximize the convenience of students daily affairs.

\section{Conclusion}

In short, under the background of the new media era, college student management is facing good development opportunities and severe challenges. The application and popularization of various new media technologies make the life and study habits of contemporary college students deeply affected, so it must be highly regarded by the college student management workers and scientifically utilize the inherent advantages of new media to realize the management of students exploring the innovative mode of work and thinking. The student management workers in colleges and universities should make full use of the function of the Wechat platform to improve the speed of information dissemination and facilitate the daily affairs of the students so that they can serve as an important tool for campus information communication and campus culture.

\section{Acknowledgements.}

The special subject of Jilin Agricultural University in 2016: the research on the effectiveness of teaching quality assurance in Jilin Agricultural University (item number: 2016JXZX06)

\section{References}

[1] http://tech.hexun.com/2016-08-18/185568734.html

[2] Yuan Lei, Chen Xiaohui. Study on mixed learning under the support of WeChat [J]. China Electrotechnical Education, 2012, 15 (7): 33-34.

[3] Bai Hao, Hao Jingjing. the Application of the WeChat public platform in the field of university [4] Wang Lili. The application of students' management of the WeChat [J]. Journal of Inner Mongolia Normal University (Education Science Edition), 2015,13 (4): 33-35.education in [J]. China Education Information Technology, 2013,16 (4): 55-56.

[5] Mao Xun. The application of the WeChat in the management of college students [J]. Health Vocational Education, 2015,16 (5): 33-34. 